\title{
Letter from . . .Chicago
}

\section{Cutting to the bone}

\author{
GEORGE DUNEA
}

In the traditional spirit of naming things by their opposites or by what they are not, we may think of health care as the care of the sick, and of the health field as the sickness field. We furthermore appreciate that the health field is no field at all, certainly not one with grass and cows and trees rustling in the wind, but at best a conglomerate of hospitals, clinics, and tall corporate towers for the pharmaceutical industry. It is also a field believed to have grown too luxuriantly, consuming $\$ 400$ billion a year or $10 \%$ of the gross national product. A week in hospital now costs more than a year in college, for which three out of four Americans insist on blaming the doctors. And everybody talks about cutting back.

The administration and Congress of course worry about the federal deficit. In the long run it is not healthy to have more money going out than coming in. In the short run they want to keep the defence budget and social security benefits but not raise taxes. This may not be realistic, however, because not enough is left to cut out of domestic programmes to make up for deficit spending. Otherwise the economy seems in good shape. There was indeed considerable euphoria at the time of the state of the nation address, when $\mathrm{Mr}$ Reagan promised a second American revolution and pointed to the favourable economic indicators, the growing emplovment and productivity, the strong dollar, the low inflation, and reduced interest rates. But the deficit keeps looming large on the horizon, and the financial markets are nervous. Yet not as nervous as the workers in the health/sickness field, who have already undergone a series of mutilating operations.

For the government the immediate target is Medicare, the $\$ 80$ million programme for some 27 million people over 65 . From this programme $\mathrm{Mr}$ Reagan would like to amputate a sizable chunk. I have already written about the growing dilemma of vast expenditures on intensive care units and complex technologies. To this must be added the certainty that in years to come there will be many more old people around, not only in Florida and Arizona but everywhere, a greying or whitening of America that will become increasingly expensive. Thus the $\$ 51$ billion spent on the people over 80 years old is expected to double by the year 2000; and there are fears that the Medicare Trust Fund may run out of money.

Meanwhile the focus is on prospective reimbursement, Medicare's grouping of all human afflictions into 468 diagnostic related groups-or DRGs as they are acronymically known. This is a hard game to play well, being ideally suited for patients with one disease, whereas many old people (and even some younger ones) are inconsiderate enough to develop more than one illness or complication. Naturally, doctors do not wish to become branded as big money losers for their hospitals, especially when many hospitals stand half empty, some at $30 \%$ occupancy, others on the point of being converted into hospices or nursing homes. So the medical records librarians are coming to play an important role, because

Cook County Hospital, Chicago, Illinois

(iEOR(GE DUNEA, FRCP, FRC.PED, attending phrsician only they understand how the codes translate into money, or why "respiratory failure" is to be preferred to "asthma" when the Pco: is 65 anyway. One Chicago hospital is currently losing an average of $\$ 10000$ for a Medicare patient treated in an intensive care unit. So it must be hard to make ends meet when an ill patient with an unprofitable disease thrashes around in a hospital bed for two weeks in a poorly reimbursed form of delirium, and it all comes out to less money than two days of acute pulmonary oedema with an ever so much more favourable diagnostic related group code. So far no hospital has gone bankrupt from the introduction of diagnostic related groups, but admissions and hospital stays have declined, and there is talk about more cuts for each group.

Lately another acronymic player has entered the field, the PROs or professional review organisations. These outfits are supposed to review charts and approve payment, and they depend for their survival on saving Medicare money. Contracts are awarded to the best bidders; and the reviewers understand that they need to be tough and deny payments or will eventually be out of a job. So new rules are constantly being promulgated; and soon doctors may have to call a central office for permission to admit patients for elective surgery. Then there is also talk of increasing Medicare deductibles and copayments, paying less for medical education, freezing or cutting the reimbursements to hospitals, maintaining the freeze on doctors' fees, or even switching them to a prospective reimbursement system. The government also wants to allow Medicare beneficiaries to sign up with prepaid medical plans (health maintenance organisations or HMOs), believing that it will be cheaper than paying hospitals and private doctors for each service. Under the contemplated arrangements a certain proportion of Medicare money would go to pay for monthly health maintenance organisation premiums. If the cost should then turn out to be less than expected the government would provide extra services such as eye glasses, prescription drugs, or dental services. Yet despite these strategies all may not be well with Medicare. Some critics worry that there will be two tiers of care, one for the rich and one for the poor. Others think that freezing reimbursement, like price controls in general, is incompatible with the dynamics of private enterprise, leading to problems and complaints and pressures that eventually must lead to the rules being changed.

\section{$\$ 4$ billion off Medicare and \$1 billion off Medicaid in 1986}

But while the health experts keep talking about new ways of delivering care, privatising or decentralising government programmes, or setting up cost effective systems, they seem to forget that a momentous revolution in the practice of medicine has already occurred. This change is our ability to treat as outpatients ever so many people who once would have lain in hospitals for weeks. It is because of powerful new drugs and other technological advances that we can do this, because of cimetidine and minoxidil and new devices not because of an army of planners and experts. But it still costs a lot of money. The budget people predict that health costs will continue to double every six years and they desperately want to cut 
back. For Medicare, the anticipated reduction is hoped to be some $\$ 4$ billion for the fiscal year 1986 , or $\$ 20$ billion for the next three years.

For 1986 the government also wants to cut $\$ 1$ billion from Medicaid, the 20 year old public aid programme covering the medical needs of some 22 million poor people. This programme costs the federal government nearly $\$ 23$ billion and the states and municipalities another $\$ 19$ billion. It is a more difficult subject to write about because every state has its own arrangements and because some have less poor and unemployed than others. Several states have limited the number of hospital days they will pay for to anywhere between 12 and 24 , after which patients become the responsibility of the municipality and may have to be transferred to a county hospital. Some 25 states now require Medicaid recipients to pay a portion of their medical fees. Some have frozen doctors' fees and others have not paid much to begin with. Still others require preadmission authorisation, more outpatient surgery and testing, and compulsory second opinions for elective surgery. In Illinois, which spends $\$ 817$ million yearly on Medicaid, the initial Reagan cuts decimated the programme. Benefits were reduced, eligibility criteria tightened, and private practice in the inner city was pretty much wiped out, the doctors closing their offices, the hospitals refusing for a time to accept certain categories of patients. Here also the government is putting its faith into prepaid health maintenance organisations, but so far experience has been mixed. Most of the inner city patients long accustomed to going to emergency rooms, often at night, complain bitterly at being told to see their doctor in the morning (unless it is a dire emergency) because otherwise the health maintenance organisation will not pay the hospital. Some of the more sophisticated patients are also dissatisfied with health maintenance organisation care, especially with being seen by a succession of young doctors but never the same twice. Then the state government is also trying to cut costs in other ways; and in Chicago the hospitals have made a bid for a certain number of Medicaid hospital days, with the initial negotiations being conducted in secret so that nobody knew what the others bid.

\section{Industry also lowering its health bill}

Also taking part in the cost campaign is industry. Recently, $\mathrm{Mr}$ Joseph Califano, former minister of health but now board member of the Chrysler Corporation, explained that Chrysler was spending seven times as much on health insurance as Mitsubishi of Japan. Specifically, health benefits for each worker cost $\$ 5700$ a year, amounting to $\$ 550$ a car. And if indeed there ever was a time when doctors and hospitals could freely charge whatever they wanted this is no longer so. Faced with ever increasing health insurance premiums, industry is now making tremendous efforts to lower its health bill through competitive bidding, second opinion programmes, and sharing costs with employees. It is also entering into arrangements with preferred provider organisations-groups of hospitals and doctors contracting to provide care under certain conditions and at a discounted rate. This leaves the hospitals, already squeezed from all sides and struggling to survive, actively forming such organisations, negotiating with employers, and offering favourable arrangements to attract more clients. They are also trying to diversify, to expand into home health care, even venturing into areas unrelated to medicine. Some of the hospitals are forming alliances to share services, buy supplies at more favourable terms, or raise money. Many of the smaller hospitals, however, may prove unable to compete successfuly and will eventually be taken over by the more efficient hospital chains.

One other part of the "health field," large though not particularly efficient, is the federal Veterans Administration system. So far this has been politically sacrosanct, even if it took a week to schedule a barium meal. But now the annual cost of paying for the 172 Veterans Administration hospitals is rising rapidly, being expected to double to almost $\$ 18$ billion by 1990 , when half of all Americans over 64 years old may be veterans. So this budget is also coming under fire, as the Reagan administration wants to freeze funds and limit benefits to individuals who cannot pay. Under the new proposals services would gradually be restricted to families earning less than $\$ 15000$ a year, with others qualifying only if their medical expenses exceeded $10 \%$ of income.

A variety of other programmes may also be cut or eliminated, depending on what is finally negotiated between the administration and the diverse interests in Congress. It all leaves many doctors hankering after the old days of "rugged individualism," when medicine was a simple transaction between doctor and patient, without the interposition of HMOs, PPOs, PROs, DRGs, and other unpleasant acronyms. It also leaves me hoping that those wielding the power will find the wisdom to cut out the fat without stripping the flesh down to the bone.
What might be a suitable hormonal contraceptive for a woman aged 23 with chronic active hepatitis controlled with prednisolone $10 \mathrm{mg}$ a day and azathioprine $50 \mathrm{mg}$ a day? She particularly wishes to use a hormonal form of protection.

The combined oral contraceptive is associated with an increased risk of cholestatic jaundice similar to that in pregnancy, and sensitive tests of liver function show changes (within the normal range) suggestive of minimal hepatocellular damage in a proportion of users. These changes tend, however, to revert to pretreatment values with continuing use, and are in any event fewer with modern low progestogen low oestrogen formulations. In this patient there will already be abnormal liver function tests; thus prudence dictates that the combined oral contraceptive should be avoided, as indeed it is during the acute phase of any other form of hepatitis and for up to six months after the liver function tests have returned to normal.' Moreover, the pharmacological effects even of the lowest dose formulations available may be higher than usual, as the liver's excretory function will be impaired. Interactions with either or both of the two drugs are also possible-for example, the actions of the prednisolone might be enhanced. ' Finally, both chronic active hepatitis and combined oral contraceptives have an association with some degree of risk of benign and malignant neoplasia of the liver. Nevertheless, the progestogen only pill would only be relatively contraindicated provided that the liver function tests were carefully monitored and showed no deterioration. This is because the progestogen dose in Microval/ Norgeston (levonorgestrel $30 \mu \mathrm{g}$ ), for example, is so small. Even tis would be contrary to the advice of other authorities. 'The ideal route of adninistration would be vaginal (to avoid the first pass effect in which the liver receives the first full impact of hormones taken by mouth). With careful monitoring it would not be fanciful to suggest taking the progestogen only pill by the vaginal route-pending the marketing of the progestogen releasing intravaginal ring. Finally, it would be preferable to avoid the intrauterine contraceptive device for this patient because any associated pelvic infection might be worsened by her immunosuppression.-JOHN GUILLEBAUD, senior lecturer in gynaecology, London.

1 Guillebaud J. The pill. Oxford: Oxford Lniversity Press, 1984:152, 159 .
2 Becley L. Are there any absolute medical contraindications to the progestogen only oral
contraceptive? Br.Med. $1984: 289: 545$.
3 Coutinho LM, Coutinho LJ, Goncalves. MT. Barbosa IC. Ovulation suppression in women
following vaginal administration of oral contraceptive tablets. Fertil Siterl 1982:38:380-1.

Can you advise on the treatment for prostatism with sitosterolin (extracted from the cormi of Hypoxis rooperi)? Is it available in some form on the market?

Sitosterolin ( $\beta$-sitosterol) is one of several liposterolic plant extracts used in France and Germany to treat benign prostatic hyperplasia. This use is based on the fact that growth of the prostate is thought to be androgen mediated, and some plant steroids have antiandrogenic properties. A related compound, Permixon, which is a liposterolic extract from the fruit of a palm tree, is used in France to treat benign prostatic hyperplasia. Permixon inhibits the binding of synthetic androgens in rat prostatic tissue ${ }^{\prime}$ in vitro but in this particular study sitosterolin was inactive. Two preparations of sitosterolin are marketed in Germany for prostatic hyperplasia: Hartzol capsules (Hoyer GmbH \& Co, Siemensstrasse 14, postfach: 1240, 4040 Neuss 21, W Germany) and Prostasal capsules (TAI) Pharmazeutisches Werk GmbH, Heinz-Lohmann-Strasse 5, postfach: 720, 2190 Cuxhaven, W Germany). No preparations are marketed in the United Kingdom.-I.INDA BEELEY, consultant clinical pharmacologist, Birmingham.

1 Carilla E, Briley M, Fauran F, Sultan (.h, Duviliters C. Binding of Permixon, a new treatment for prostatic benign hyperplasia, to the cytosolic androgen receptor in the rat prostate. F Sterond
Biochem 1984:20:521-3. 